\title{
Overview of the Mars climate station for Tianwen-1 mission
}

\author{
YongQing Peng 1", LeiBo Zhang ${ }^{1}$, ZhiGuo Cai' , ZhaoGang Wang1', HaiLong Jiao', DongLi Wang1', XianTao Yang1',

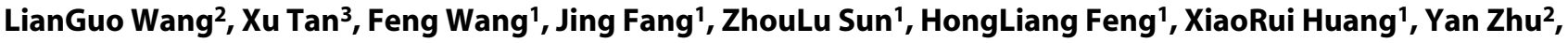 \\ Ming Chen ${ }^{1}$, LiangHai $\mathrm{Li}^{1}$, and YanHua $\mathrm{Li}^{4}$ \\ 1Beijing Research Institute of Telemetry, Beijing 100076, China; \\ ${ }^{2}$ National Space Science Center, Chinese Academy of Sciences, Beijing 100012, China; \\ ${ }_{3}^{3}$ National Astronomical Observatories, Chinese Academy of Sciences, Beijing 100012, China; \\ ${ }^{4}$ Chinese Academy of Aerospace Electronics Technology, Beijing 100012, China
}

Citation: Peng, Y. Q., Zhang, L. B., Cai, Z. G., Wang, Z. G., Jiao, H. L., Wang, D. L., Yang, X. T., Wang, L. G., Tan, X., Wang, F., Fang, J., Sun, Z. L., Feng, H. L., Huang, X. R., Zhu, Y., Chen, M., Li, L. H., and Li, Y. H. (2020). Overview of the Mars climate station for Tianwen-1 mission. Earth Planet. Phys., 4(4), 371-383. http://doi.org/10.26464/epp2020057

\begin{abstract}
The background and scientific objectives of the Mars Climate Station (MCS) for Tianwen-1 are introduced, accompanied by a comparative review of the status of related meteorological observation missions and of advanced sensing technologies. As one of the China Tianwen-1 Mission's principal scientific payloads, the MCS contains four measurement sensors and one electronic processing unit that are specially designed to measure local temperature, pressure, wind, and sound on the Martian surface. The MCS's measurement principles, technical schemes, ground calibration techniques, and adaptability evaluation to the Mars surface environment of MCS are introduced in details. The conclusion presents measurement performance specifications of the MCS, based on ground test results, that will provide guidance to future research based on data from the Tianwen- 1 and later Mars missions.
\end{abstract}

Keywords: Tianwen-1; Mars exploration; Mars climate station

\section{Introduction}

In recent years, rapid progress in the development of space technology has been accompanied by increased international interest in Mars exploration. Many nations' Mars missions have included payloads consisting of meteorological survey instruments designed to collect data crucial to preparations for human exploration of the surface of Mars. Viking (Chamberlain et al., 1976), Pathfinder (Seiff et al., 1997; Sullivan et al., 2000), Beagle 2 (Towner et al., 2004), Phoenix (Taylor et al., 2008; Gunnlaugsson et al., 2008), Curiosity (Mueller et al., 2006; Domínguez et al., 2008; Gómez-Elvira et al., 2012), InSight (Pont et al., 2018), and other Mars probes all have included meteorological measurement payloads (Williams, 2001; Lorenz, 2004). They have successfully measured such meteorological parameters as air temperature, pressure, and wind field of the landing point or patrolling area, but none have obtained direct reliable sound data characterizing the surface of Mars. In 1999, NASA launched the Mars Polar Lander, for detecting sound on the surface of Mars (Delory et al., 2007). The Mars Polar Lander lost contact after entering the Mars atmosphere during the landing phase. In 2007, Phoenix was launched by NASA; and the ESA's surround detected sound signals during its descent and landing process, but the microphone part of the

Correspondence to: Y. Q. Peng, pengyq@brit.com.cn

Received 26 MAY 2020; Accepted 16 JUN 2020.

Accepted article online 30 JUL 2020.

C 2020 by Earth and Planetary Physics.
Phoenix mission was never turned on due to compatibility issues regarding the avionics of the probe (Murdoch et al., 2019). The InSight mission (InSight Mission News, 2018, 2019) launched by NASA in 2018, used a pressure sensor to measure dynamic pressure signals and raised them two octaves to make them audible to the human ear, but these are not actual sounds within the normal range of human hearing.

China's first Mars exploration mission, named Tianwen-1, was announced by the China National Space Administration on April 24, 2020, the fifth National Space Day of China. The probe is expected to be launched by a Long March 5 Y4 carrier rocket in Summer 2020. The mission consists of an orbiter that will travel around Mars, and a lander with a rover that will travel on Martian soil. The Mars Climate Station (MCS), developed by the Beijing Research Institute of Telemetry, is one of the most important scientific instruments aboard the Mars rover. It will investigate the Martian climate and environmental characteristics, aiming to measure simultaneously the atmosphere, temperature, pressure, wind field, and sound at the Martian surface.

\section{Instrument Description}

Mars exploration missions are high risk and resource constrained; accordingly, precision measurement instrument payloads must meet demanding specifications. Small size, light weight, low power consumption, and high stability and reliability over a wide range of operating temperatures were among the challenging requirements that the MCS was designed to meet. 
The MCS consists of four units: Measurement Unit 1 (MU1), Measurement Unit 2 (MU2), an Instrument Control Unit (ICU), and a Cable kit. The MU1 accommodates a temperature sensor array and a gas filtering head for its pressure sensor; its total weight is about $183 \mathrm{~g}$, and its dimensions are roughly $54 \mathrm{~mm} \times 57 \mathrm{~mm} \times$ $40 \mathrm{~mm}$. The MU2 accommodates a wind sensor and an optic-fiber microphone; its weight is approximately $217 \mathrm{~g}$, and its size is about $110 \mathrm{~mm} \times 110 \mathrm{~mm} \times 91 \mathrm{~mm}$. The ICU is placed in the Mars Rover cabin to give it a somewhat more moderate temperature environment, while the MU1 and MU2 are installed outside the Mars Rover cabin in order to be exposed directly to the Martian surface atmosphere. The locations of the MU1 and MU2 on Mars Rover are shown in Figure 1; the general framework of the MCS is shown in Figure 2.

The Instrument Control Unit is composed of a pressure sensor array and an electronic board. The functions of the electronic board include power management, sensor signal transfer, data acquisition, data processing, and a communication interface. The Cable Kit is divided by two plies of cables connecting the ICU with the MU1 and MU2, respectively. The cable between the MU1 and the ICU includes a ply of electric cables for transmitting the temperature sensor signal to the ICU, and a stainless steel tube with inner diameter of $1 \mathrm{~mm}$ for connecting the pressure sensor in the ICU

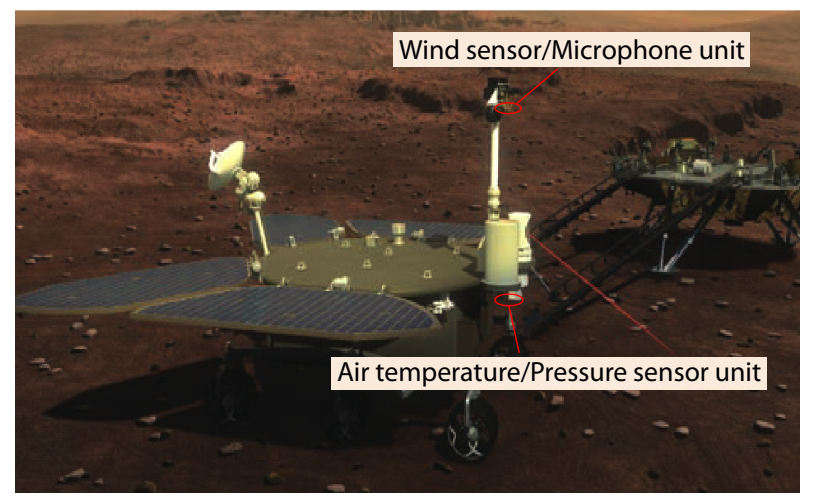

Figure 1. The location of MCS sensor unit on Mars Rover. with the outside atmosphere through a gas filter head. Similarly, the cable between the MU2 and the ICU includes a ply of electric cables for transmitting the wind sensor signal, and a fiber for transmitting the optic signal. The average power consumption of the MCS is $4.53 \mathrm{~W}$; its peak power is $11.13 \mathrm{~W}$.

The operation mode of the MCS includes a conventional mode and a maneuvering mode. In the course of the in-orbit working process, measurements will be made according to predesigned instructions, using the conventional mode; MU1 and MU2 will be collecting data at the same time. In order to ensure successful completion of the scientific mission, the validity of the telemetry data is analyzed first. Then the maneuvering mode could be adopted accordingly to adjust the working parameters (such as their sampling rate, sampling time, magnification times, compression ratio, et al.).

\section{Measurement Principle}

\subsection{Temperature Measurement}

The key technologies considered in the design and implementation process for the measurement of Martian air temperature are: (1) the design of special radiation protection shields for the air temperature sensor was required to isolate it from solar radiation and other stray radiation, thereby reducing the measuring error caused by radiant heating to an acceptable range; (2) optimum miniaturization of the device's size while also insuring its physical compatibility with the meteorological conditions of Mars was a critical criterion; (3) establishing a theoretical model of the heat conduction to the sensor from the Martian air, but also from all other sources of heat, was required in order to determine a correction algorithm to eliminate the impact of the Mars Rover's own heating and ambient radiation on the accuracy of the air temperature measurement.

The air temperature sensor array consists of three PT1000 platinum resistance thermometers (PRTs) as the temperature sensitive components; the PRTs are located at the top, middle, and bottom of a PCB bracket, as shown in Figure 3.

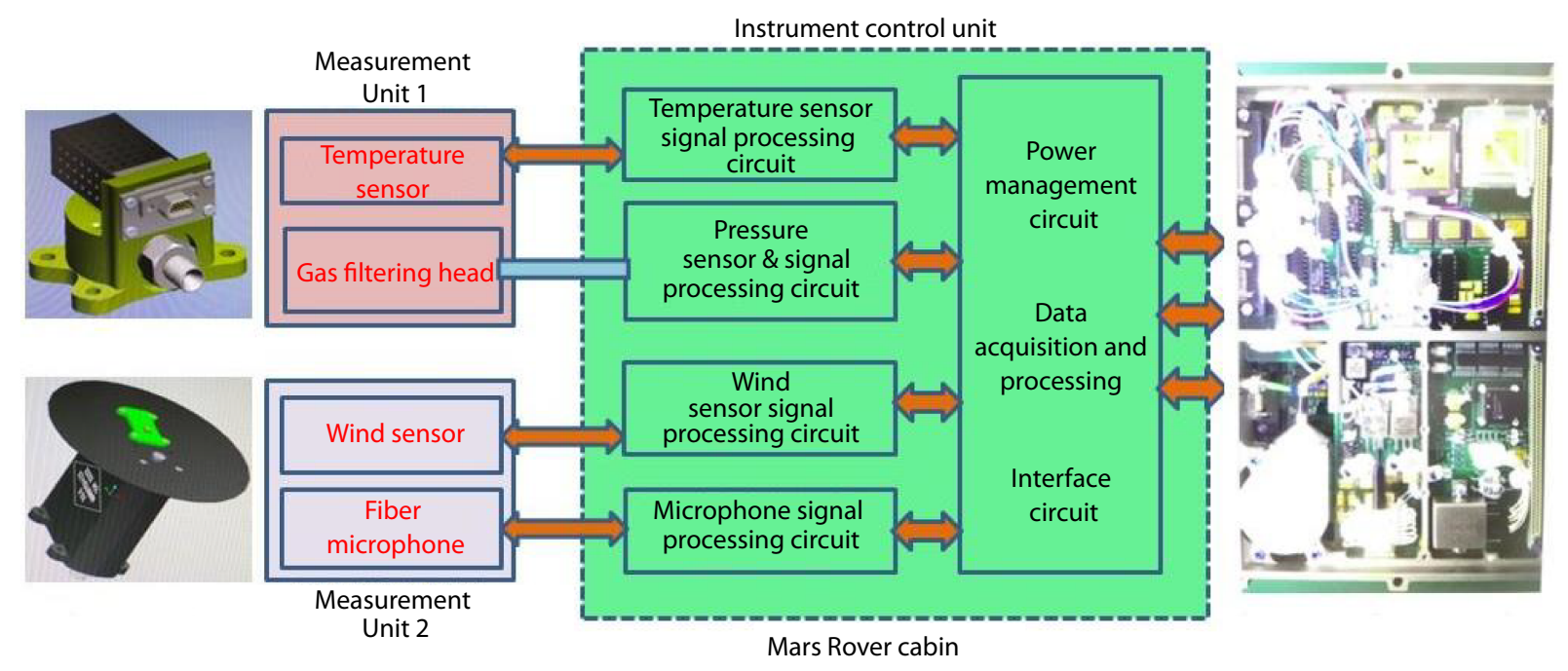

Figure 2. The general framework of the Mars Climate Station. 

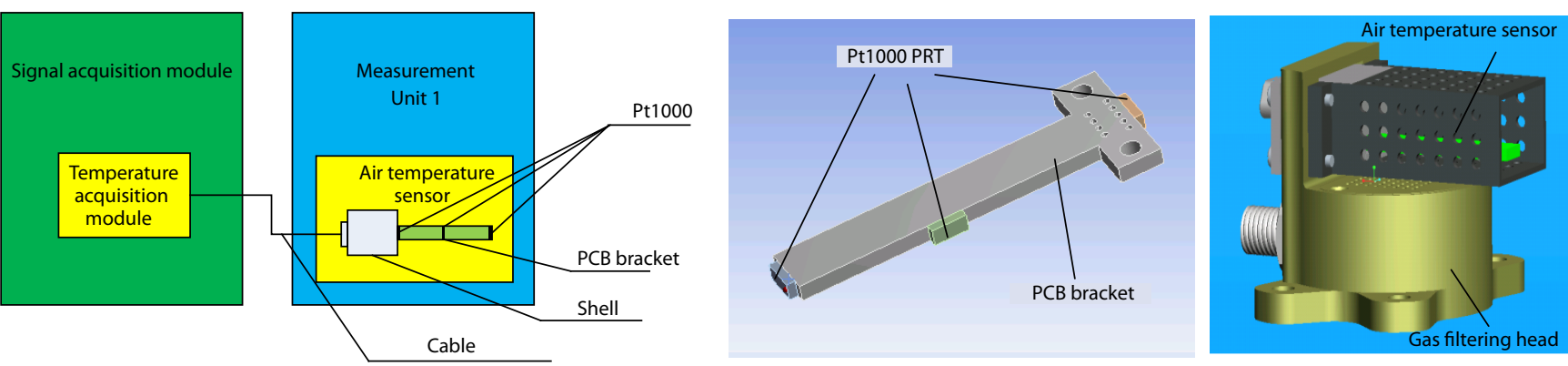

Figure 3. Schematic diagram of air temperature measurement.

The main part of the air temperature sensor is a PCB bracket with three sensitive elements located at different points. A simplified schematic is shown in Figure 4. The PCB bracket is considered as a long cuboid, and the three temperature measurement points are located at $x=0, x=L$ and $x=1 / n L$ respectively. Based on the model, a heat conduction microelement is established. $Q_{x}$ is the heat flowing into the microelement. $Q_{x+\mathrm{dx}}$ is the heat flowing out of the microelement. $Q_{\text {loss }}$ is the heat loss on the surface of the microelement. The heat balance equation is given by (Mueller et al., 2006)

$$
Q_{x}-Q_{x+d x}-d Q_{\text {loss }}=0 .
$$

Considering the expression of conduction, convection, and radiation, the above equation can be written as

$$
\frac{\mathrm{d}}{\mathrm{d} x}\left(k A_{c} \frac{\mathrm{d} T}{\mathrm{~d} x}\right)-h_{c} \frac{\mathrm{d} A_{s}}{\mathrm{~d} x}\left(T-T_{\text {sur }}\right)-\varepsilon \sigma \frac{\mathrm{d} A_{s}}{\mathrm{~d} x}\left(T^{4}-T_{\text {sur }}^{2}\right)=0 .
$$

In this equation, $k$ is the thermal conductivity, $h_{c}$ is the convective heat transfer coefficient, $\varepsilon$ is the emissivity, $\sigma$ is the Boltzmann constant, $T_{\text {sur }}$ is the ambient temperature, $A_{c}$ is the cross section area of the microelements, $A_{s}$ is the surface area, and $A_{c}=a b$, $A_{s}=(2 a+2 b) \mathrm{d} x$.
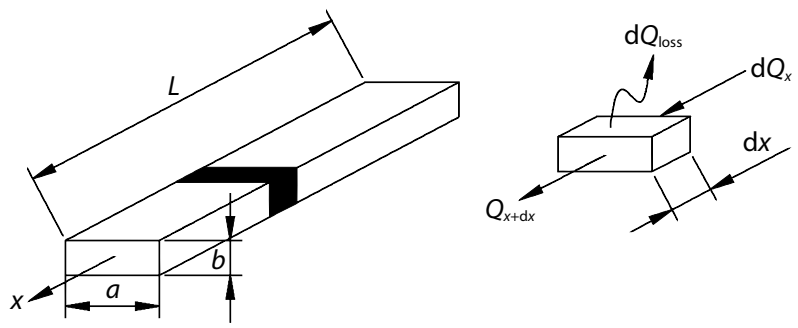

Figure 4. Air temperature sensor model and a microelement.

The boundary condition at $x=0$ is given by

$$
\left.T\right|_{x=0}=T_{b},
$$

where $T_{b}$ is the temperature of the bottom of the bracket.

For the point $x=L$, the boundary condition under steady-state conditions is given by

$$
\left.\frac{\mathrm{d} T}{\mathrm{~d} x}\right|_{x=L}=0 .
$$

Then the analytical solution of the equation can be obtained:

$$
T-T_{\text {sur }}=\left(T-T_{b}\right) \frac{\cosh [m(1-\chi)]}{\cosh m},
$$

where

$$
\begin{gathered}
m=\sqrt{\frac{2 a+2 b}{a b k} h,} \\
h=h_{\mathrm{rad}}+h_{\mathrm{con},} \\
h_{\mathrm{rad}}=\varepsilon \sigma\left(T^{2}+T_{\text {sur }}^{2}\right)\left(T+T_{\text {sur }}\right), \\
x=\frac{x}{L} .
\end{gathered}
$$

The temperature of the two points $x=L$ and $x=L / n$ can be measured as $T_{1}$ and $T_{2}$, then

$$
\begin{gathered}
T_{1}-T_{\text {sur }}=\left(T_{b}-T_{\text {sur }}\right) \frac{1}{\cosh m^{\prime}} \\
T_{2}-T_{\text {sur }}=\left(T_{b}-T_{\text {sur }}\right) \frac{\cosh [m(1-\chi)]}{\cosh m} .
\end{gathered}
$$

From Equation (10) and (11), the environmental temperature $T_{\text {sur }}$ can be obtained.

\subsection{Pressure Measurement}

The scheme for measuring pressure on the Martian surface is shown in Figure 5. The pressure sensor array is integrated into the ICU which is located in the Mars Rover cabin. A gas filtering head is installed on the outer plate of the Mars Rover with a gas tube; the filtering head, is designed to protect the pressure sensor from Martian dust. The sensor element is connected to the atmosphere through the stainless gas tube and the gas filtering head. This pressure measurement scheme has been designed to provide high reliability in the harsh environment on the surface of Mars. The pressure sensor array incorporates three MEMS pressure sensors, a redundancy that can further improve the reliability of the pressure data.

As shown in Figure 6, the MEMS pressure sensor, based on a capacitance sensitive mechanism, consists of a cavity glass layer (glass2), a silicon membrane, a substrate glass layer (glass-1), electrode plates, pads, and a thin Ti getter layer. The glass-2 layer and the silicon membrane form a reference vacuum cavity, which achieves a high vacuum level and thus high reliability in the Ti getter. The glass-1 layer and the silicon membrane, together with electrode plates 1 and 2, form a pressure sensitive capacitor. High reliability is realized by the design of the external electrode plates presented in Figure 6, which avoids any need for an electrode outside the reference vacuum cavity. Such a design ensures the hermeticity of vacuum in the harsh environment on the Marian surface. The capacitance varies with the changing of the gap between the 


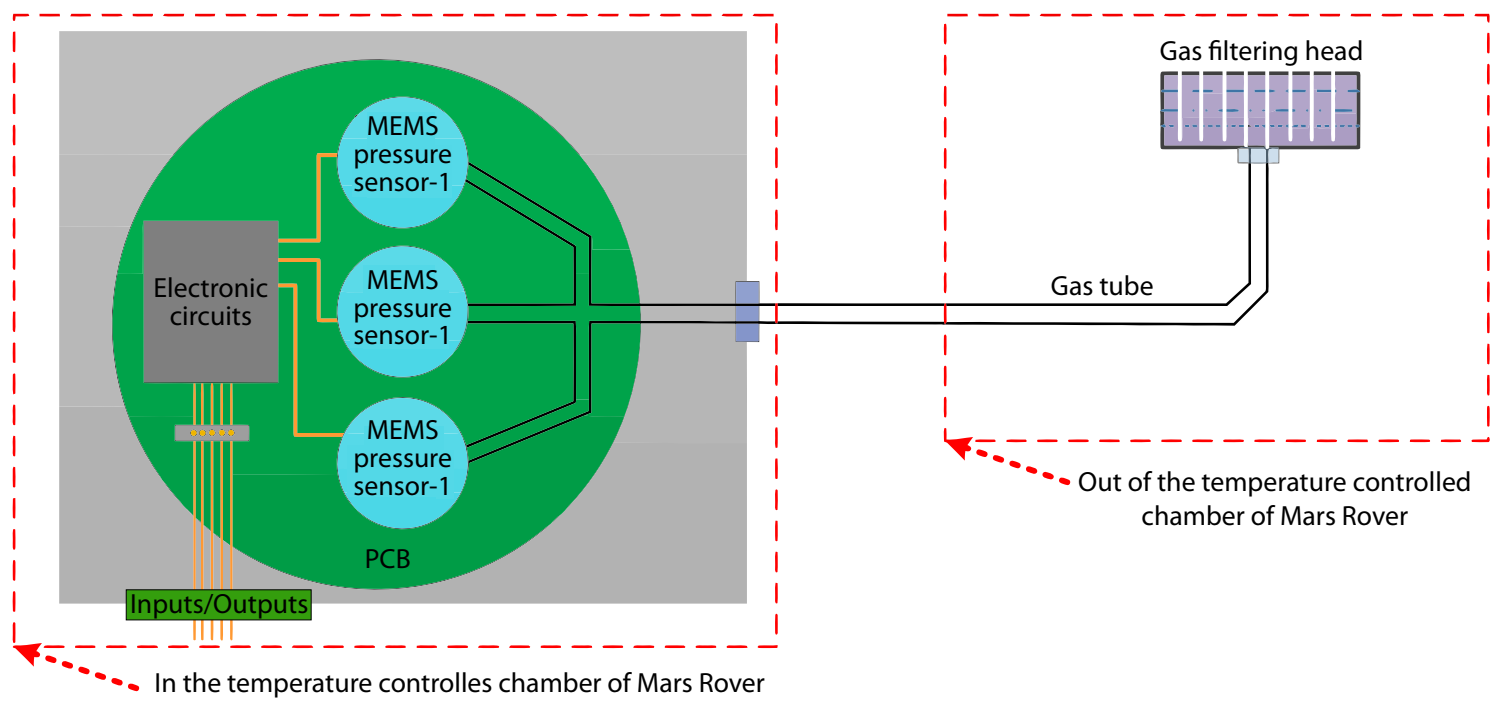

Figure 5. Schematic illustration of device for pressure measurement on the surface of Mars.

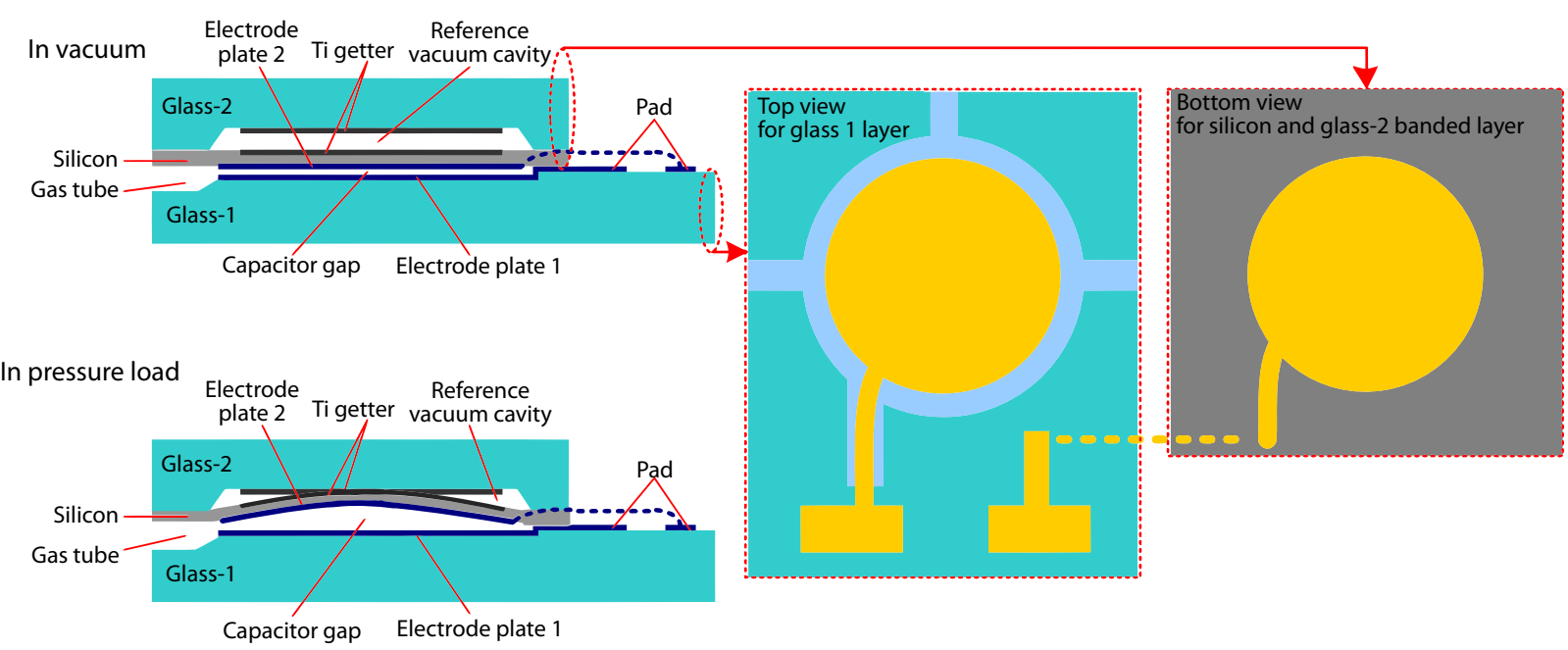

Figure 6. Schematic illustration of the MEMS pressure sensor for exploring the surface of Mars.

two electrode plates due to fluctuation of the load pressure. The capacitance can be measured by the digital converter (CDC) electronic circuit. The glass-silicon-glass three layers micro sensing structure ensures the reliability of the vacuum seal and makes electrode extraction highly convenient. The $S$ type micro gap tube design is helpful in further filtering of possible dust particles.

The MEMS pressure sensor chip is fabricated in a 4 inch MEMS cleaning facility, which includes many processes, such as cleaning, lithography, Cr\&Au deposition, Cr\&Au etching, glass etching, silicon wet etching, silicon DRIE, lapping, lift-off, getting activation, and glass-silicon-glass three layer anodic bonding for vacuum packing with ultra-low residual stress. Figure $7(a, b, c)$ shows pictures of the MEMS pressure sensor chip and packaging.

A 24-bit CDC ASIC chip is used for measuring the variable capacitance of the MEMS pressure sensor chip, which also can measure the temperature at the same time, in the form of 24-bit binary data. Capacitance ranging from $6 \mathrm{pF}$ to $14 \mathrm{pF}$ can be measured with $30 \mathrm{aF}$ resolution. Meanwhile, temperature ranging from $-40^{\circ} \mathrm{C}$ to $+125^{\circ} \mathrm{C}$ can be obtained with $0.1^{\circ} \mathrm{C}$ resolution; accurate temperature data allow a compensation algorithm to be applied to data from the pressure sensor to obtain higher accuracy. Figure $7(d, e)$ show the scheme of the capacitive signal detecting circuit and the pressure sensor prototype.

\subsection{Wind Field Measurement}

The thermal film measurement principle was adopted for the wind measurement. The schematic diagram of the Mars surface wind field sensor is shown in Figure 8. The sensor head design features a hot end and a cold end. The hot end is composed of four sensor chips. Each chip is composed of a temperature sensing resistor and a heating resistor. The cold end is used to obtain the ambient temperature. The wind sensor adopts the constant temperature difference (CTD) working mode. The heating resistor heats the hot end sensors to maintain a constant temperature difference $\Delta T$ relative to the ambient temperature. The heating power on the four sensor chips is $W_{1}, W_{2}, W_{3}$ and $W_{4}$ respectively. The total power consumed at the hot end changes as a function of the 

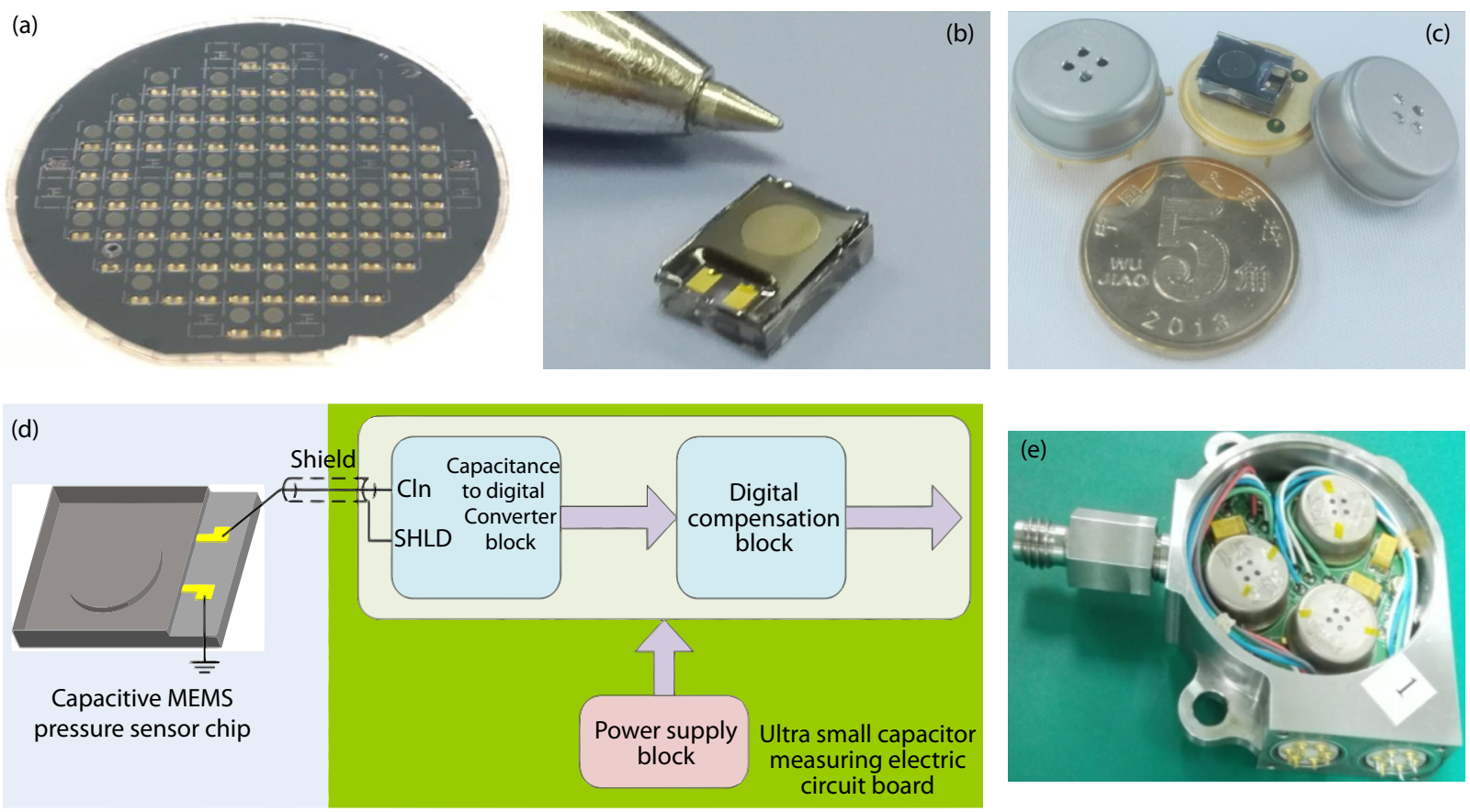

Figure 7. Pictures of the MEMS pressure sensor for exploring the surface of Mars. (a) Pressure sensor wafer; (b) Pressure sensor chip; (c) Pressure sensor packaging; (d) Scheme of capacitive signal detecting circuit; (e) Pressure sensor prototype.
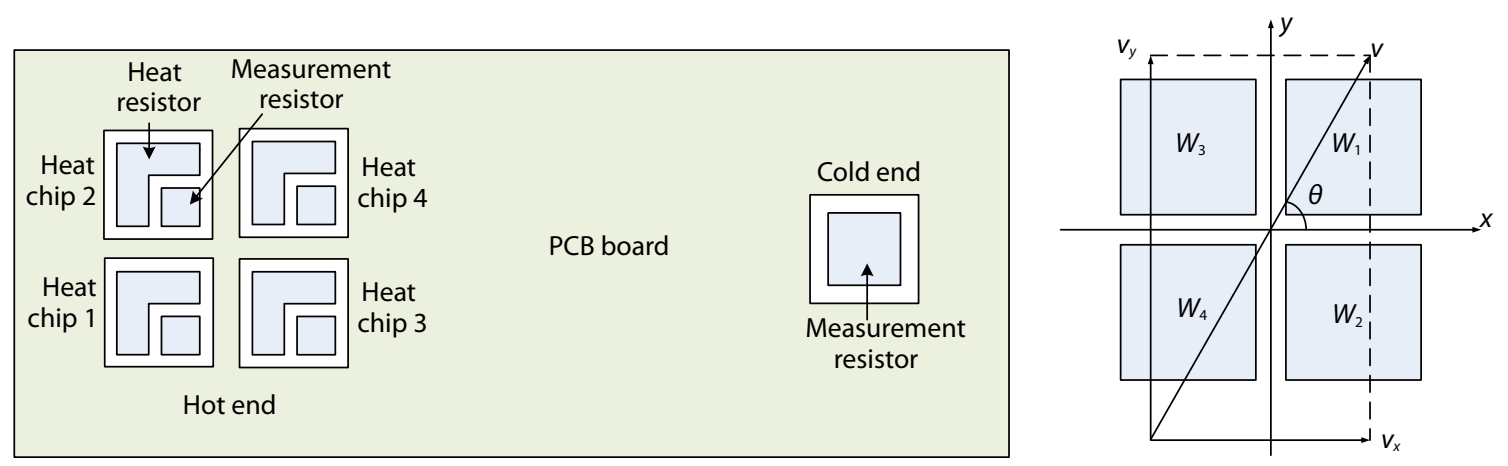

Figure 8. Schematic diagram of Mars surface wind field sensor.

wind speeds. The relative changes of the heating power of the four sensors at the hot end will be different according to changes in the wind direction $\theta$. The wind direction $\theta$ can be obtained through Equations (12)-(17).

$$
\begin{gathered}
X=W_{1}+W_{2}-W_{3}-W_{4}, \\
Y=W_{1}+W_{3}-W_{2}-W_{4}, \\
\theta=\arctan (Y / X), \text { when } X>0, Y>0, \\
\theta=\pi+\arctan (Y / X), \text { when } X<0, Y>0, \\
\theta=\pi+\arctan (Y / X), \text { when } X<0, Y<0, \\
\theta=2 \pi+\arctan (Y / X), \text { when } X>0, Y<0 .
\end{gathered}
$$

A micro structure based on the MEMS process was designed for the bottom of the hot end sensitive chip to increase the heat insulation to the PCB board. This insulation greatly reduces the sensors' power consumption and increases their sensitivity. Therefore, accurate and reliable measurement of wind speed in the low pressure Martian atmosphere is achieved.

\subsection{Acoustic Measurement}

A Mars microphone has been developed, based on optical fiber sensing. The schematic diagram and a photo of the microphone are shown in Figure 9. Its sensor includes a diaphragm, the optical fiber, and auxiliary support structures; the diaphragm and support structures are made of special alloys chosen for their very low thermal expansion coefficients. The demodulation system and the operating principle of the Mars microphone are shown in Figure 10. Light emitted by a tunable laser is transmitted to the sensor through the fiber coupler, and reflected by the diaphragm. The diaphragm is dynamically deformed by the pressure of the sound wave. Therefore, the acoustic wave modulates the reflected light signals. The reflected light passes again through the coupler and is received by the photoelectric detector. A data processing unit converts the optical signal into the acoustic information. The fiber optic sensor is installed on the outside mast of the Mars Rover; the photoelectric demodulator is in the rover's ICU. Connecting them is a 3 meters long radiation-resistant optical cable. The fiber optic 

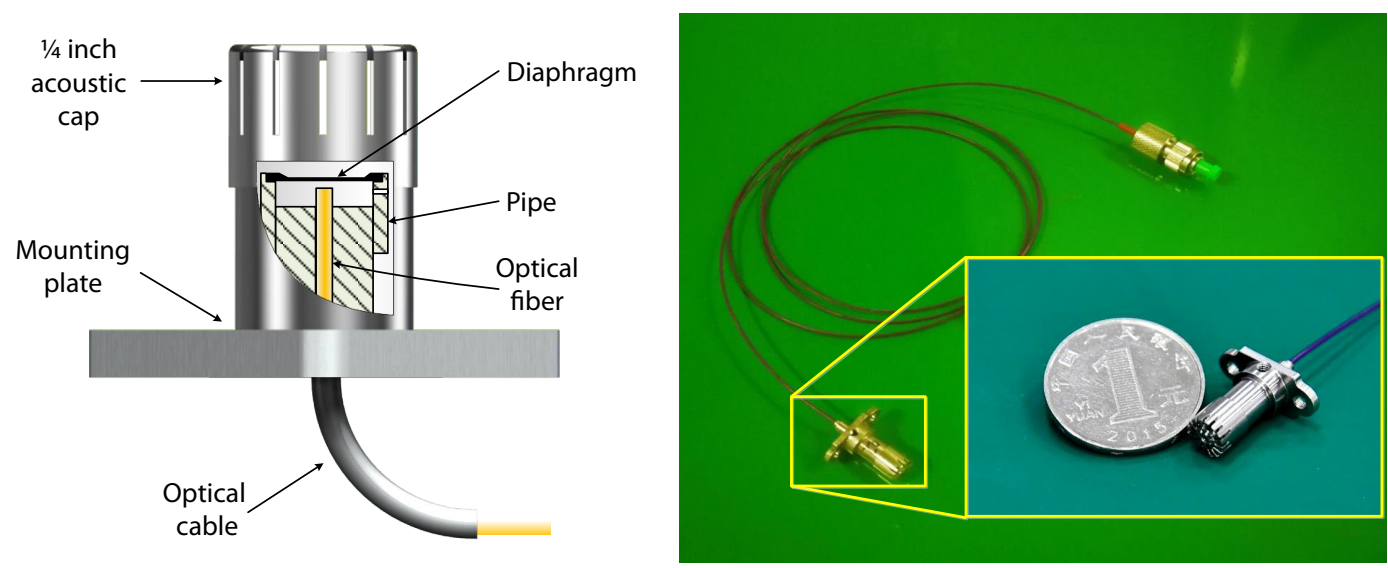

Figure 9. The schematic diagram and photo of the Mars microphone.

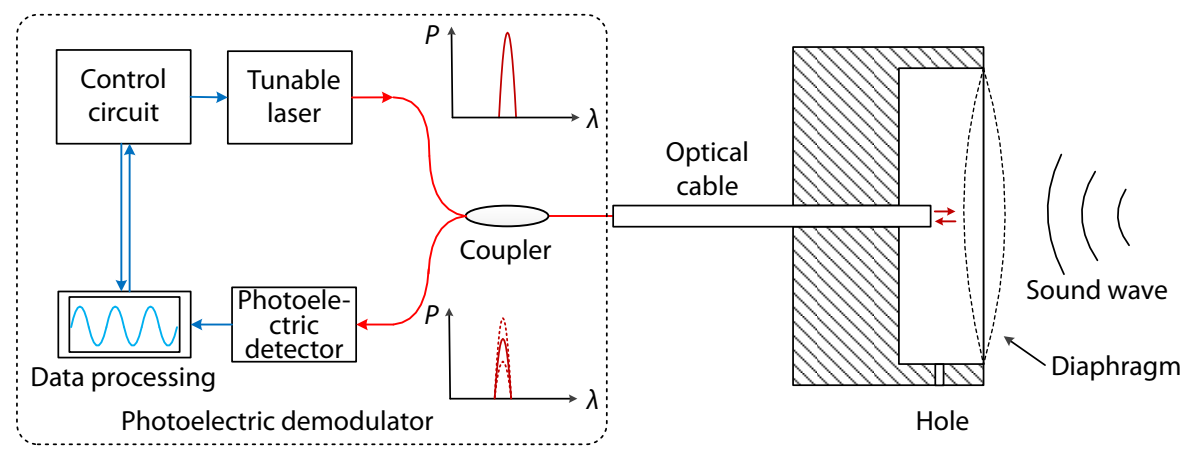

Figure 10. Mars surface microphone system.

sensor can withstand the harsh Martian environment, solving the challenge presented of making acoustic measurements over such a wide range of temperature as found on the surface of Mars. The Mars microphone's demodulator is equipped with four modifiable amplification gains, of $1 \times, 4 \times, 16 \times$, and $64 \times$.

\section{Experimental Results}

\subsection{Temperature}

A high-precision constant temperature liquid tank was used to verify the accuracy of the payload's air temperature sensor. A schematic diagram of the calibration process is shown in Figure 11a. The Mars air temperature sensor and a reference standard sensor were placed in the tank simultaneously in close proiximity to each other. The difference between the measurement results of the two sensor, over the range from $-60^{\circ} \mathrm{C}$ to $55^{\circ} \mathrm{C}$, is taken as the error of the Mars air temperature sensor. Test results show that the maximum temperature error of the Mars sensor is $0.68^{\circ} \mathrm{C}$.

In order to investigate the sensor's performance below $-60^{\circ} \mathrm{C}$, the Mars and reference standard sensors were placed in a refrigeration chamber cooled by liquid nitrogen. Figure $11 \mathrm{~b}$ shows results at the $-124^{\circ} \mathrm{C}$ temperature point. The three platinum measurement results labeled 1\#, 2\#, 3\#, and the air temperature $T$ calculated by Formulae (10) and (11) are shown in Figure 11b; the error was less than $0.6^{\circ} \mathrm{C}$ in the temperature range of $-60^{\circ} \mathrm{C}$ to $-124^{\circ} \mathrm{C}$. To test the resolution of the Mars air temperature sensor, the temperature of the liquid tank was set at $0^{\circ} \mathrm{C}$ and $0.1^{\circ} \mathrm{C}$; as shown in Figure 11c, the sensor's resolution is obviously better than $0.1^{\circ} \mathrm{C}$.

\subsection{Pressure}

To verify performation of the Mars pressure sensor, a testing and calibrating system was established; as shown in Figure 12, it included a low pressure control sub-system, a reference pressure sensor, a nitrogen high pressure vessel, a vacuum pump sub-system, a gas/vacuum tube, a DC power supplier, and a data collecting electrics sub-system and computer, etc.

An MKS 690 A pressure monitoring unit was the reference pressure sensor; it is capable of measuring pressures from $0-3.3 \mathrm{kPa}$ with $\pm 0.05 \%$ F.S. accuracy. The accuracy of the low pressure controller was $\pm 0.15 \%$ F.S. Although the major components of air on the surface of Mars are carbon dioxide (95.3\%), nitrogen (2.7\%), argon $(1.6 \%)$, oxygen $(0.15 \%)$, and water vapor $(0.03 \%)$ (Towner et al., 2004), nitrogen alone could be used to calibrate the pressure sensor because the difference between the electronic inductivity constants of various gases is very small at low pressure $(< \pm 0.001 \%)$.

The MEMS pressure sensor was calibrated by measuring its output data at several controlled pressure points $x_{i}(1,100,300,600$, $900,1200,1500,1600,2000 \mathrm{~Pa})$ at several stable temperature points $y_{j}\left(-40^{\circ} \mathrm{C},-20^{\circ} \mathrm{C}, 0^{\circ} \mathrm{C},+20^{\circ} \mathrm{C},+55^{\circ} \mathrm{C}\right)$, after high-low temperature cycling, high-low pressure cycling, and vibration testing were carried out. Three up-down cycles of controlled points were 


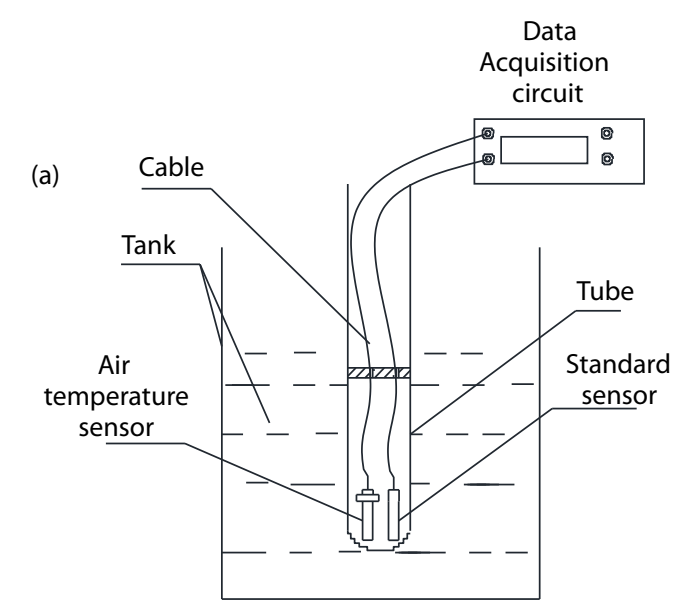

(b)

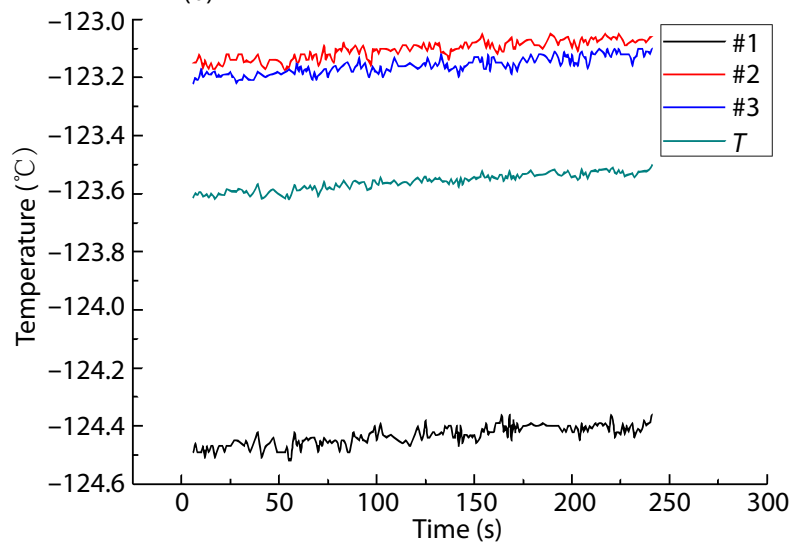

(c)

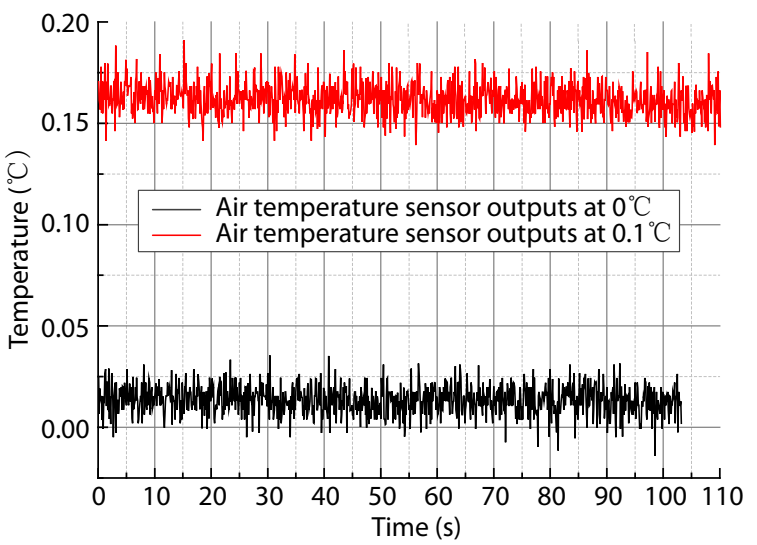

Figure 11. Air temperature sensor calibration. (a) Schematic diagram of calibration equipment; (b) Low temperature tests; (c) Resolution tests.
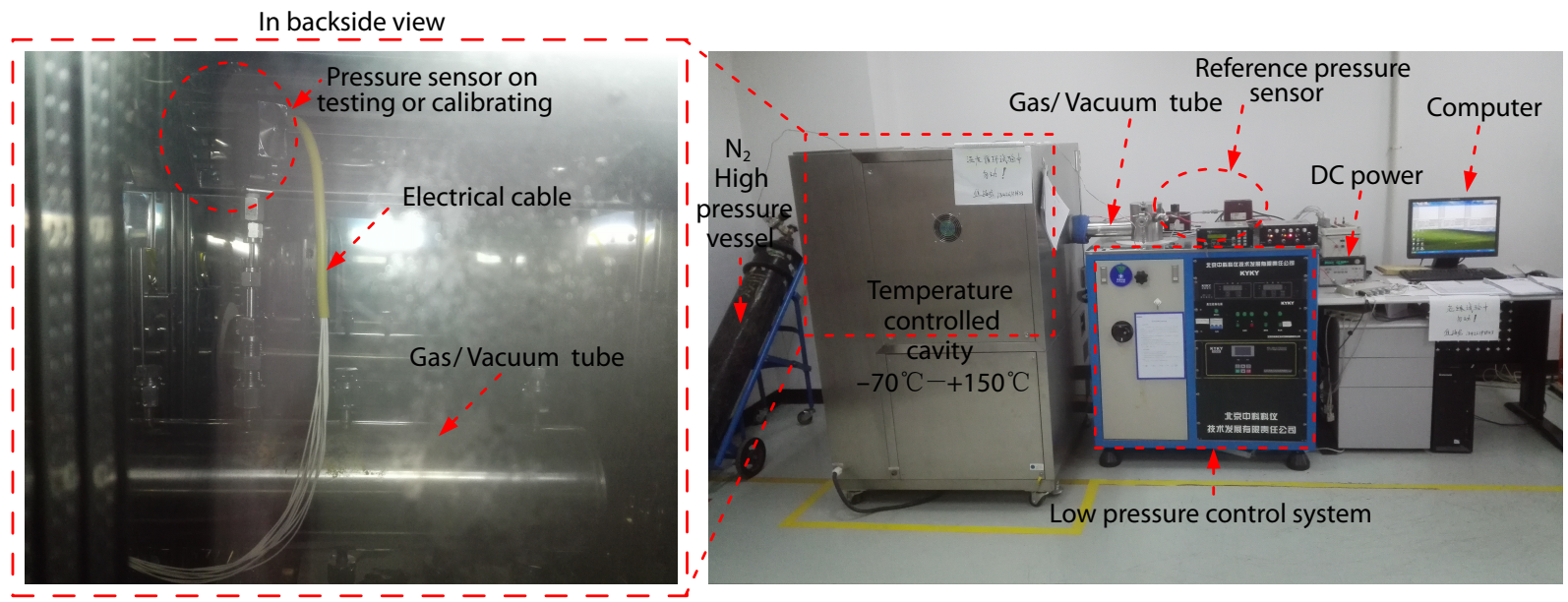

Figure 12. Test system for the MEMS pressure sensors.

averaged to arrive at the calibration result. Then the 24-bit capacitance data and 24-bit temperature data were analyzed. The temperature data were used to compensate for the thermal lag effect.

The averages of six collections of output data at different pressure points and different temperature points form a $5 \times 9$ two-dimension data sheet. These data were processed using a surface fitting algorithm taken from commercial professional math software to achieve a formula $P=f_{P}(x, y)$, as shown in Figure 13 .
The testing of the MEMS pressure sensor was very similar to its calibration. A 5 (temperature) $\times 9$ (pressure) $\times 6$ (data) could be achieved. The differences between reference pressures and measured pressures were obtained using the formula $P=f_{P}(x, y)$.

Test results show that, for the 3 MEMS pressure sensors, accuracy was better than $\pm 0.35 \%$ F.S. (i.e. max error $\leq \pm 7 \mathrm{~Pa}$ ) in the range from $1 \mathrm{~Pa}$ to $2000 \mathrm{~Pa}$ over a working temperature range of $-40^{\circ} \mathrm{C}$ to $+55^{\circ} \mathrm{C}$. The resolution measured better than $0.076 \mathrm{~Pa}$ (based on 


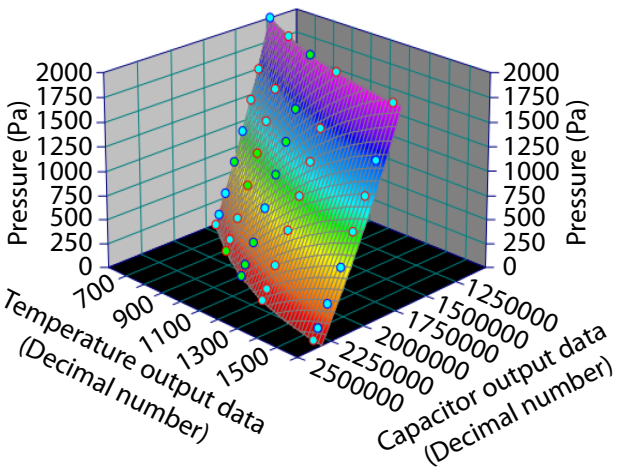

$$
\begin{aligned}
& P=a_{1}+\frac{b_{1}}{x}+c_{1} y+\frac{d_{1}}{x^{2}}+e_{1} y^{2}+f_{1} \frac{y}{x}+\frac{g_{1}}{x^{3}}+h_{1} y^{3}+i_{1} \frac{y^{2}}{x}+j_{1} \frac{y}{x^{2}} \\
& a_{1}=-388.449725972004726 \\
& b_{1}=-10822242047.2306042 \\
& c_{1}=-0.0704235257570739128 \\
& d_{1}=+44006594089595530.3 \\
& e_{1}=-0.00134719469550045302 \\
& f_{1}=+31234979.7445926615 \\
& g_{1}=-3.86591387251695342 \times 10^{22} \\
& h_{1}=+4.46126986993893298 \times 10^{-7} \\
& i_{1}=-3548.91651140891056 \\
& j_{1}=-43503582490364.2869
\end{aligned}
$$

Figure 13. Calibration results for MEMS pressure sensor.

RMSE (Root Mean Square Error)), and the 100-hours long-term stability was better than $\pm 0.15 \%$ F.S., as shown in Figure 14 . Furthermore, the characteristics of the MEMS pressure sensors remained very consistent after being loaded for more than 12 months in Beijing at $1 \mathrm{~atm}$ pressure, as a reliability test.

\subsection{Wind Field}

Based on Reynolds number correction (Gómez-Elvira et al., 2012), high-precision calibrations and related theoretical studies under low pressure conditions were accomplished, and verified by ground test.

The special environmental factors on the Mars surface, such as low atmospheric pressure, wide temperature range, and special air components, could affect the accuracy of the wind sensor measurements. It was therefore necessary to calibrate the sensor
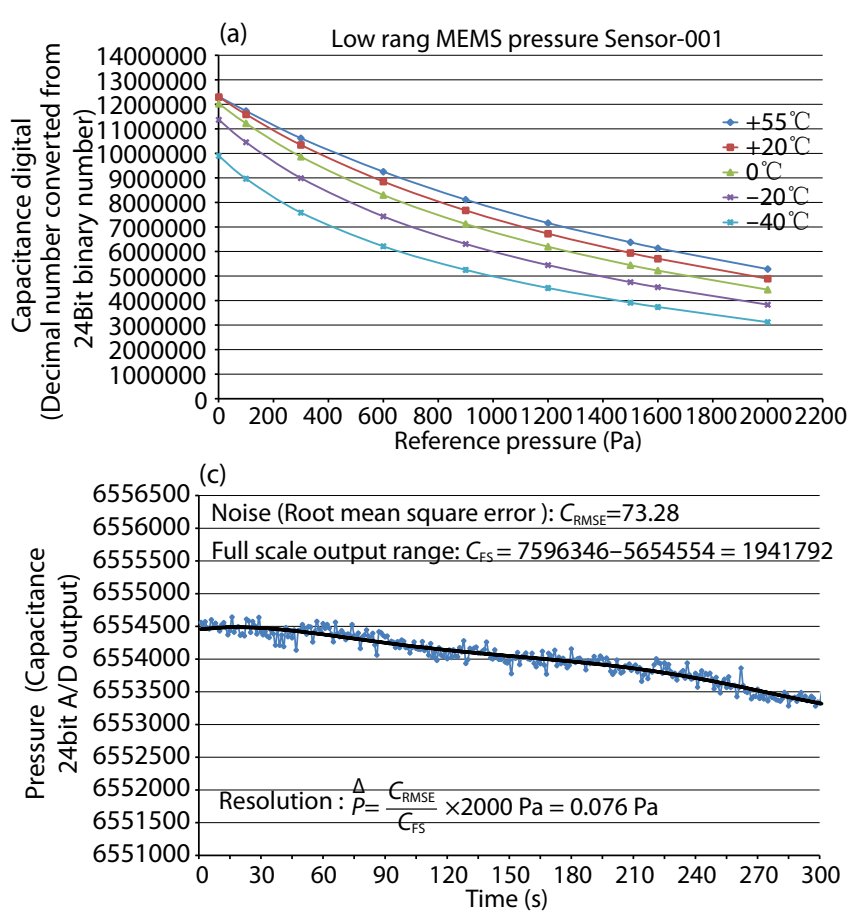

measurement results with high accuracy.

Figure 15a shows the equipment developed for ground calibration of the Mars surface wind sensor. The main part of the calibration device is a rectangular sealed cavity with dimensions $0.5 \mathrm{~m} \times$ $0.5 \mathrm{~m} \times 2 \mathrm{~m}$. Arranged inside are three temperature sensors and a pressure sensor to monitor the temperature and pressure parameters in the cavity. Cavity pressure during testing can be adjusted from $500 \mathrm{~Pa}$ to atmospheric pressure. $\mathrm{CO}_{2}$ is the working medium in the test cavity during calibration testing, chosen because more than $95 \%$ of the Martian atmosphere consists of $\mathrm{CO}_{2}$ (Kasting, 1991; Mahaffy et al., 2013). On the bottom of the cavity is a high-precision slide rail that can generate speeds of $0-2 \mathrm{~m} / \mathrm{s}$. The wind sensor is mounted on this slide rail. Moving the sensor on the rail allows calibration of its wind speed measurements in the range of $0-2 \mathrm{~m} / \mathrm{s}$. For wind speeds higher than $2.0 \mathrm{~m} / \mathrm{s}$, indirect calibration is obtained by modifying the Reynolds number.

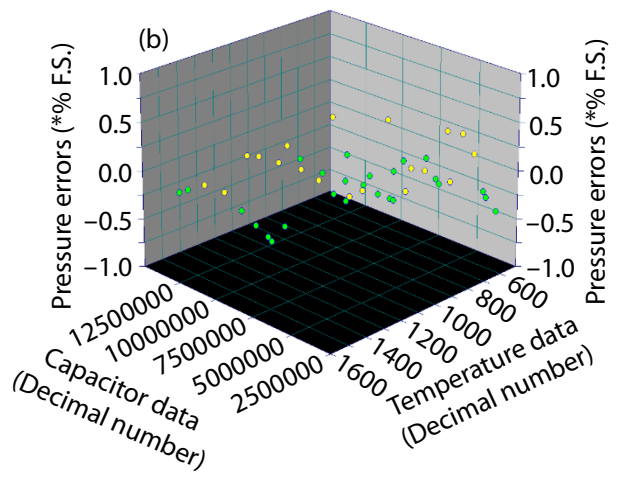

(d)

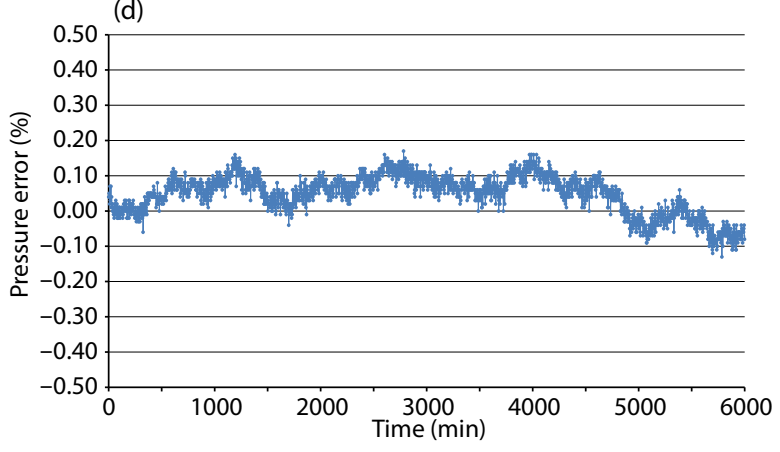

Figure 14. Results of MEMS pressure sensor testing. (a) Capacitance response vs. pressure at different temperatures; (b) Pressure errors (*\% F.S.); (c) Pressure resolution based on RMSE; (d) Stability over 100 hours (*\% F.S.). 

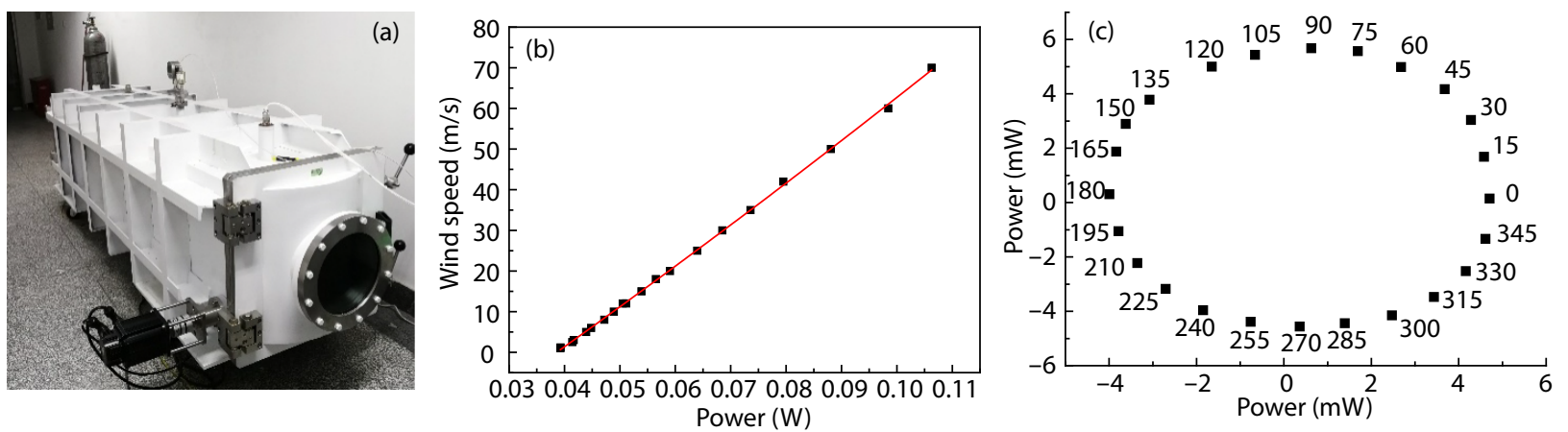

Figure 15. The calibration device and the calibration results. (a) Calibration equipment; (b) Wind speed calibration results; (c) Wind direction calibration results.

Figures $15 \mathrm{~b}$ and $15 \mathrm{c}$ present the wind speed and direction calibration results obtained at room temperature. The total outputs of the four wind sensor chips change as a quadratic function of wind speed. The outputs of the four chips change not only with the wind speed but also as a function of wind direction. The calibration results show that at room temperature, wind speed is measured with an accuracy of about 1.5\% F.S; the accuracy of wind direction measurement is better than $15^{\circ}$.

The wind sensor is calibrated at room temperature, but the actual ambient temperatures on Mars will be different and variable, so is necessary to correct the measurement results according to the actual expected Martian surface temperature range. It is known that the forced convection power $W$ is given by (Incropera et al., 2007)

$$
W=h S \Delta T \text {. }
$$

In Equation (18), $h$ is the convective heat transfer coefficient, $S$ is the area of the sensitive chip, and $\Delta T$ is the temperature difference between the hot-end sensitive chip and the ambient temperature. Due to the constant temperature difference working mode, $\Delta T$ does not change during the measurements.

$$
\begin{gathered}
h=\frac{k}{l} N u, \\
N u=C \operatorname{Re}^{m} \operatorname{Pr}^{n}, \\
\operatorname{Re}=\frac{\mathrm{N}}{v} .
\end{gathered}
$$

In Equatioons (19)-(21), $k$ is the thermal conductivity, $I$ is the characteristic length of the sensitive chip, $\mathrm{Nu}$ is the Nusser number, Re is the Reynolds number, $P r$ is the Prandtl number, $V$ is the wind speed, and $v$ is the kinematic viscosity; $C, m$, and $n$ are constants. The constants $m$ and $n$ are usually chosen as $1 / 2$ and $1 / 3$, respectively. In the temperature range of $-60^{\circ} \mathrm{C}$ to $55^{\circ} \mathrm{C}, \mathrm{Pr}^{1 / 3}$ of carbon dioxide remains almost constant. For simplification and approximate treatment, the variation of Prandtl number with temperature is ignored. If the calibrated ambient temperature is $T_{0}$, heat loss due to forced convection is assumed to be $W_{0}$. The actual measured ambient temperature is $T_{1}$, and the heat loss due to forced convection is $W_{1}$. If both cases have the same wind speed, we have

$$
\frac{W_{0}}{W_{1}} \frac{h_{0}}{h_{1}}=\left(\frac{k_{0}}{k_{1}}\right)\left(\frac{v_{0}}{v_{1}}\right)^{m}
$$

The variation of thermal conductivity $k$ and kinematic viscosity $v$ as a function of temperature $T$ was taken from literature in the range of $-60^{\circ} \mathrm{C}$ to $55^{\circ} \mathrm{C}$ (Zhang JR and Zhao YT, 1987). Then the curve of $\log (k)$ vs $\log (T)$, and $\log (v)$ vs $\log (T)$ was plotted and fitted respectively, as shown in Figures $16 \mathrm{a}$ and $\mathrm{b}$. As can be seen, $\log (k)$ and $\log (T)$, and $\log (k)$ and $\log (v)$ both have excellent linear relationships.

From the results of Figure 16, we have

$$
\begin{aligned}
& \frac{k_{0}}{k_{1}}=\left(\frac{T_{0}}{T_{1}}\right)^{1.379,}, \\
& \frac{v_{0}}{v_{1}}=\left(\frac{T_{0}}{T_{1}}\right)^{1.892} .
\end{aligned}
$$

For the thermal conductivity used in Formula (17), the temperature $T_{k}$ is usually given by

$$
T_{k}=\frac{1}{2}\left(T+T_{\infty}\right)
$$

where $T$ is the surface temperature of heat chips and $T_{\infty}$ is the ambient temperature.

From Equations (22)-(25):

$$
\frac{W_{0}}{W_{1}}=\left(\frac{2 T_{0}+\Delta T}{2 T_{1}+\Delta T}\right)^{1.379}\left(\frac{T_{0}}{T_{1}}\right)^{-1.892 m} .
$$

The Equation (26) is the formula that corrects the wind field sensors' results at different ambient temperatures. In order to verify the correctness of this method, the ground calibration equipment was put into a thermostat to change its ambient temperature. Equipment limitations restricted the range of the temperature test to $-20^{\circ} \mathrm{C}$ to $30^{\circ} \mathrm{C}$. The value of the test wind speed was 0.5 $\mathrm{m} / \mathrm{s}$ at $50 \mathrm{kPa}$ (equivalent to $25 \mathrm{~m} / \mathrm{s}$ at $1000 \mathrm{~Pa}$ ); the test was performed at the following temperatures: $-20^{\circ} \mathrm{C},-10^{\circ} \mathrm{C}, 0^{\circ} \mathrm{C}, 10^{\circ} \mathrm{C}$, $20^{\circ} \mathrm{C}$, and $30^{\circ} \mathrm{C}$. The maximum error after use of the correction formula was found to be $1.9 \mathrm{~m} / \mathrm{s}$.

\subsection{Sound}

A Brüel \& Kjaer type 9721 acoustic calibration system was used to calibrate the acoustic sensitivity and frequency response of the microphone. The voltage-sound pressure sensitivity is 68.14 $\mathrm{mV} / \mathrm{Pa} @ 250 \mathrm{~Hz}$ and $1 \times$ gain. The frequency response curve of the microphone within $20 \mathrm{~Hz}-20 \mathrm{kHz}$ is shown in Figure 17a. The flatness in the range of $5 \mathrm{kHz}$ is better than $\pm 0.5 \mathrm{~dB}$. A Brüel \& Kjaer 9719 high acoustic pressure level calibration system was used to 

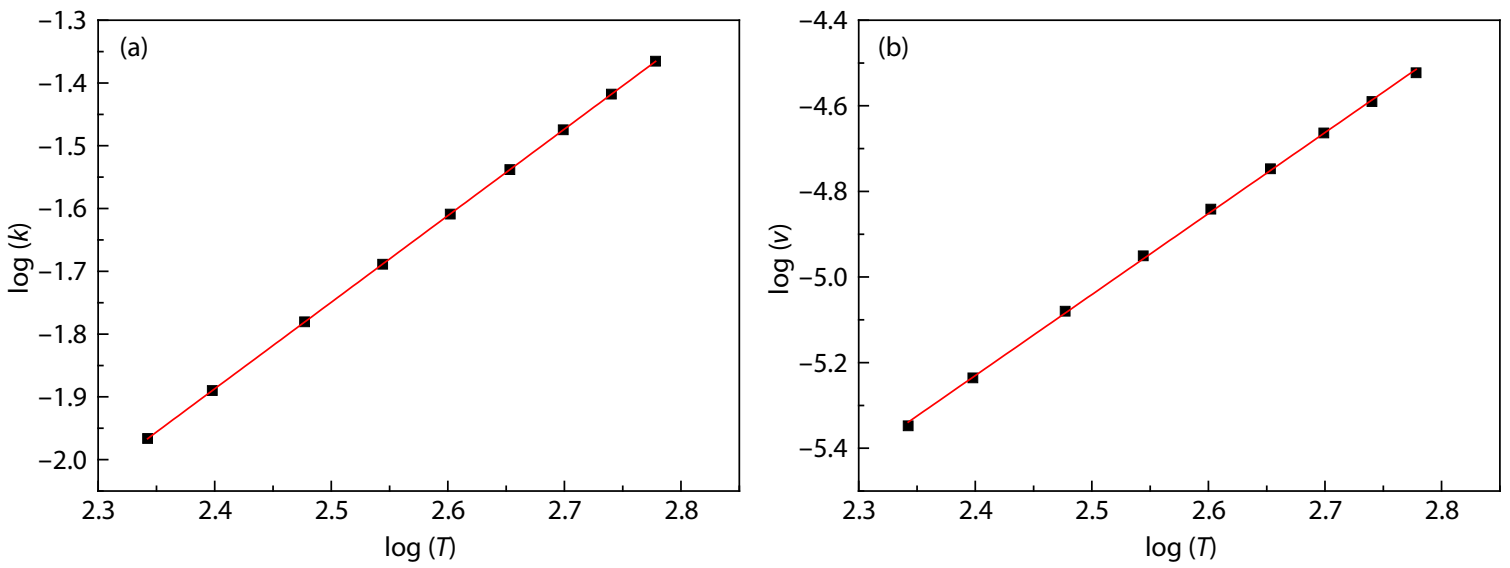

Figure 16. The relationship between physical properties of Mars atmospheric media $\left(\mathrm{CO}_{2}\right)$ and temperature. (a) Relationship of $\log (T)$ vs $\log (k)$; (b) Relationship of $\log (T)$ vs $\log (v)$.
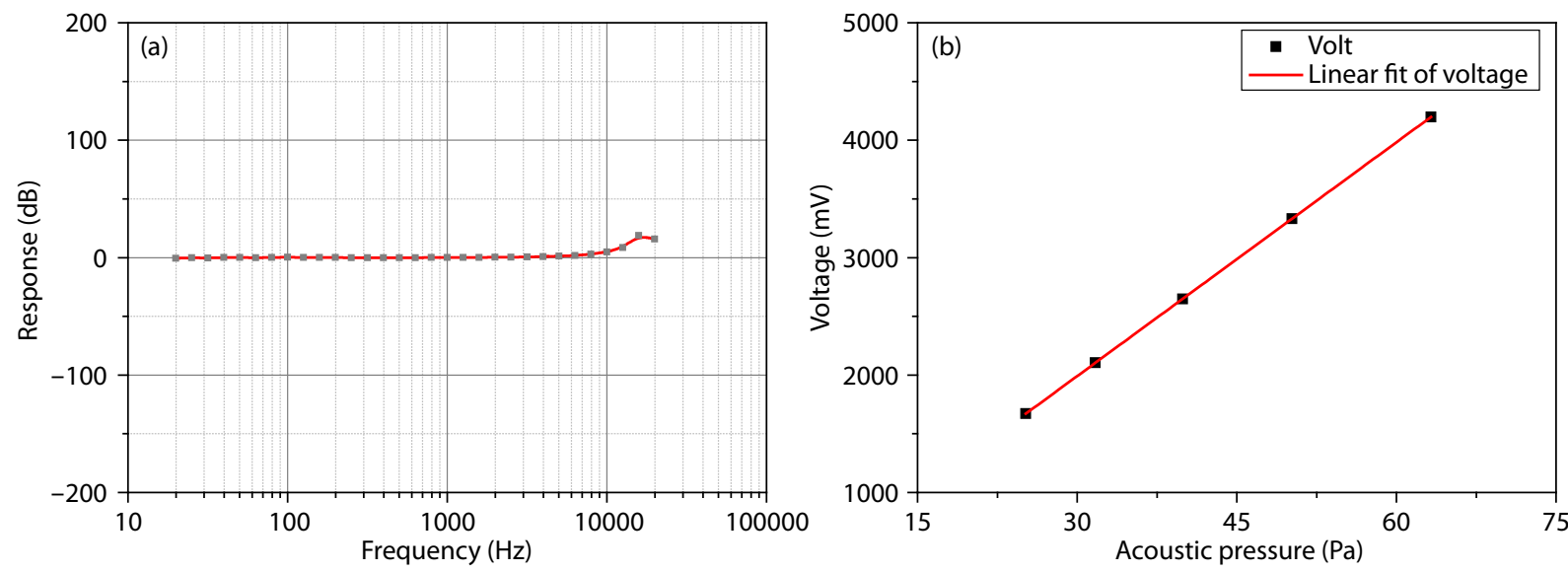

Figure 17. The calibration results of Mars surface microphone. (a) Response vs frequency results; (b) The linearity of acoustic pressure results.

calibrate the linearity. As shown in Figure 17b, the microphone remains linear (the distortion is less than $3 \%)$ below $130 \mathrm{~dB}(\sim 63.2$ $\mathrm{Pa})$ at $500 \mathrm{~Hz}$. The equivalent dynamic range has been calculated as $96.12 \mathrm{~dB}$ according to the background electric noise.

To study the temperature response of the microphone in the range of $-60^{\circ} \mathrm{C}$ to $55^{\circ} \mathrm{C}$, a test platform was built. As shown in Figure 18 , sound waves produced by a standard sound generator $(124 \mathrm{~dB}, 250 \mathrm{~Hz})$ propagate into the high-low temperature chamber through a rigid sound conduit; the Mars microphone in the chamber is connected to the end of the conduit. The pigtail fiber of the microphone is connected to the photoelectric demodulator via an optical cable through the chamber. The acoustic pressure produced by the sound generator is invariable, so the changing output voltages of the photoelectric demodulator at different temperatures could reflect changes in the sensitivity of the sensor.

Use $0 \mathrm{~dB}=1 \mathrm{~V}$ as reference, equivalent sound pressure level $L_{U}$ can be calculated as

$$
L_{U}=20 \lg (U / 1)
$$

where $U\left(V_{\mathrm{rms}}\right)$ is the effective value of output voltage.

The sensitivity response deviation $\Delta M(\mathrm{~dB})$ is defined as

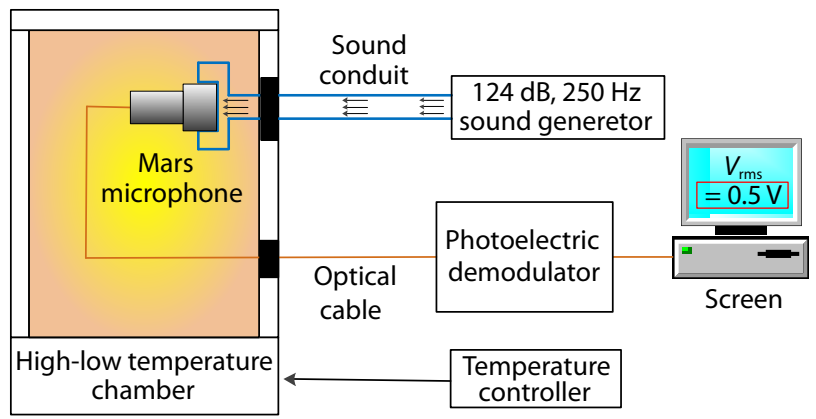

Figure 18. The temperature response test platform of Mars surface microphone.

$$
\Delta M=L_{U}-\left(L_{U \max }+L_{U \min }\right) / 2,
$$

where $L_{U \max }(\mathrm{dB})$ is the maximum value of the equivalent voltage level under all testing temperatures, and $L_{U \min }(\mathrm{dB})$ is the minimum value.

The testing temperatures were $-60^{\circ} \mathrm{C},-40^{\circ} \mathrm{C},-20^{\circ} \mathrm{C}, 0^{\circ} \mathrm{C}, 20^{\circ} \mathrm{C}$, $40^{\circ} \mathrm{C}$, and $55^{\circ} \mathrm{C}$. The sensitivity response deviations under different temperatures are shown in Figure19. It can be seen that the total response deviation of the Mars microphone is $\pm 2.35 \mathrm{~dB}$ within the temperature range of $-60^{\circ} \mathrm{C}$ to $55^{\circ} \mathrm{C}$. 


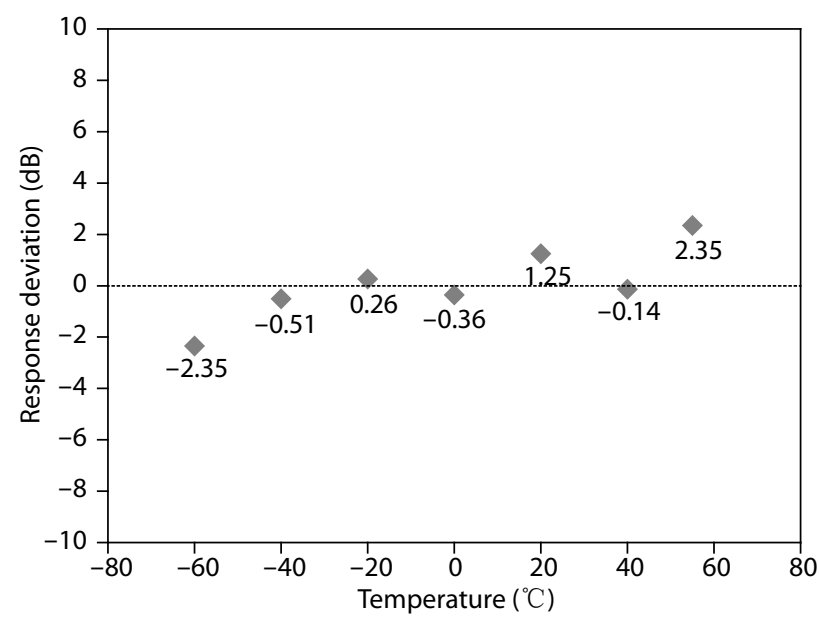

Figure 19. The sensitivity response deviations of the Mars microphone at different temperatures.

\subsection{Ground Environment Test}

In order to verify the stability and reliability of the entire system of the MCS, ground environmental tests have been carried out on the assembled payload. The main conditions of these tests are listed in Table 1.

The main performance parameters of the MCS were measured after the environment tests to evaluate the environmental adaptability of the MCS. These post-environmental test measurement results are shown in Table 2.

It can be seen from the measurement results that, after the environment tests, the MCS still performed well, indicating that the meteorological instrument can be relied on to perform with good reliability and stability in conditions expected on Mars.

\subsection{MCS Specifications Summary}

The main performance of the MCS is summarized, and a comparative list of MCS and other meteorological stations flown to the Mars surface is shown, in Table 3 . It can be seen that in addition to the measurement of environmental parameters such as air temperature, pressure, and wind field, a significant feature of the MCS is its ability to measure sound parameters.

\section{Conclusion}

This paper has presented a detailed introduction to the Mars Climate Station payload for China's Tianwen-1 mission. In order to ensure compatibility to the special space environment on the surface of Mars, the MCS instrument has been designed to have the characteristics of small size, low power consumption, light weight, and high resistance to shock, vibration, radiation, and to the Martian environmental challenges presented by sandstorm. The measurement principles and schemes adopted to measure accurately temperatures, pressures, wind fields, and sounds on the Martian surface are described. The instrument specifications have been validated by laboratory calibration and ground environment experiments. The performance of the MCS payload instruments have been demonstrated to be prepared to meet the objectives of China's first Mars exploration mission.
Table 1. Ground environmental test conditions.

\begin{tabular}{|c|c|}
\hline Test item & Test condition \\
\hline Random vibration test & $\begin{array}{l}20-100 \mathrm{~Hz},+6 \mathrm{~dB} / \mathrm{oct} \\
100-2000 \mathrm{~Hz}, 0.036 \mathrm{~g}^{2} / \mathrm{Hz} \\
\text { Acceleration root-mean-square, } 8.34 \mathrm{~g}\end{array}$ \\
\hline $\begin{array}{l}\text { Low pressure discharge } \\
\text { tests (ground simulation } \\
\text { Mars environment) }\end{array}$ & $\begin{array}{l}0.1-1350 \mathrm{~Pa}, \mathrm{~N}_{2} \text { environment } \\
\text { Room temperature } \\
\text { Test number, } 3 \text { times }\end{array}$ \\
\hline Thermal vacuum test & $\begin{array}{l}\leq 6.65 \times 10^{-3} \mathrm{~Pa} \\
-45 \text { to }+60^{\circ} \mathrm{C} \text { for ICU } \\
-125 \text { to }+60^{\circ} \mathrm{C} \text { for MU1 } \\
-65 \text { to }+60^{\circ} \mathrm{C} \text { for MU2 } \\
\text { Cycle-index, } 3.5 \text { times }\end{array}$ \\
\hline $\begin{array}{l}\text { Thermal vacuum test } \\
\text { (ground simulation Mars } \\
\text { environment) }\end{array}$ & $\begin{array}{l}150-1350 \mathrm{~Pa}, \mathrm{~N}_{2} \text { environment } \\
-45 \text { to }+60^{\circ} \mathrm{C} \text { for ICU } \\
-125 \text { to }+60^{\circ} \mathrm{C} \text { for MU1 } \\
-65 \text { to }+60^{\circ} \mathrm{C} \text { for MU2 } \\
\text { Cycle-index, } 3.5 \text { times }\end{array}$ \\
\hline Heat cycle test & $\begin{array}{l}\text { Ambient pressure } \\
-45 \text { to }+60^{\circ} \mathrm{C} \text { for ICU } \\
-125 \text { to }+60^{\circ} \mathrm{C} \text { for MU1 } \\
-65 \text { to }+60^{\circ} \mathrm{C} \text { for MU2 } \\
\text { Cycle-index, } 12.5 \text { times }\end{array}$ \\
\hline $\begin{array}{l}\text { High temperature storage } \\
\text { test }\end{array}$ & $\begin{array}{l}+75^{\circ} \mathrm{C} \text { for ICU, MU1 and MU2 } \\
\text { Holding time, } \geq 12 \mathrm{~h} \\
\text { Cycle-index, } 4 \text { times }\end{array}$ \\
\hline $\begin{array}{l}\text { Low temperature storage } \\
\text { test }\end{array}$ & $\begin{array}{l}-55^{\circ} \mathrm{C} \text { for ICU } \\
-125^{\circ} \mathrm{C} \text { for MU1 and MU2 } \\
\text { Holding time, } \geq 12 \mathrm{~h} \\
\text { Cycle-index, } 4 \text { times }\end{array}$ \\
\hline Cyclic sophistication test & $\begin{array}{l}\text { Ambient pressure } \\
-125 \text { to }+60^{\circ} \mathrm{C} \text { for MU1 } \\
-65 \text { to }+60^{\circ} \mathrm{C} \text { for MU2 } \\
\text { Cycle-index, } 20 \text { times } \\
-45 \text { to }+60^{\circ} \mathrm{C} \text { for ICU } \\
\text { Cycle-index, } 30 \text { times }\end{array}$ \\
\hline
\end{tabular}

Table 2. The comparison of measurement results after the environmental test with the calibration results before the test.

\begin{tabular}{|c|c|c|}
\hline Variable & $\begin{array}{l}\text { Measurement results after } \\
\text { environment test }\end{array}$ & $\begin{array}{l}\text { Calibration results before } \\
\text { environment test }\end{array}$ \\
\hline $\begin{array}{l}\text { Surface air } \\
\text { temperature }\end{array}$ & $\begin{array}{c}\text { Accuracy: } \\
\left.0.087 \mathrm{~K} \text { (measured at } 0^{\circ} \mathrm{C}\right) \\
\text { Resolution: } \\
0.1 \mathrm{~K}\left(\text { measured at } 0^{\circ} \mathrm{C}\right)\end{array}$ & $\begin{array}{l}\text { Accuracy: } \\
\pm 0.68 \mathrm{~K} \\
\text { Resolution: } \\
0.1 \mathrm{~K}\end{array}$ \\
\hline Pressure & $\begin{array}{c}\text { Accuracy: } \\
5 \mathrm{~Pa} \text { (measured at } 0 \mathrm{~Pa} \\
20^{\circ} \mathrm{C} \text { ) }\end{array}$ & $\begin{array}{c}\text { Range: } \\
1 \mathrm{~Pa}-20 \mathrm{hPa} \\
\text { Accuracy: } \\
\pm 0.35 \% \text { F.S. }( \pm 7 \mathrm{~Pa})\end{array}$ \\
\hline Wind & $\begin{array}{c}\text { Wind speed range: } \\
0-70 \mathrm{~m} / \mathrm{s} \\
\text { Wind speed accuracy: } \\
1.1 \mathrm{~m} / \mathrm{s} \text { (measured at } 70 \\
\mathrm{~m} / \mathrm{s} \text { ) } \\
\text { Wind direction accuracy: } \\
6.8^{\circ} \text { (measured at } 90^{\circ} \text { ) }\end{array}$ & $\begin{array}{c}\text { Wind speed range: } \\
0-70 \mathrm{~m} / \mathrm{s} \\
\text { Wind speed accuracy: } \\
1.9 \mathrm{~m} / \mathrm{s} \\
\text { Wind direction accuracy: } \\
15^{\circ}\end{array}$ \\
\hline Sound & $\begin{array}{c}\text { Sensitivity: } \\
72.57 \text { mV/Pa@250 Hz }\end{array}$ & $\begin{array}{c}\text { Sensitivity: } \\
68.14 \text { mV/Pa@250 Hz }\end{array}$ \\
\hline
\end{tabular}


Table 3. Comparison between MCS and other meteorological stations flown to the Mars surface.

\begin{tabular}{|c|c|c|c|c|}
\hline Variable & Mars pathfinder & Phoenix & Curiosity & Tianwen-1 \\
\hline Launch time & 1996 & 2007 & 2011 & 2020 \\
\hline $\begin{array}{l}\text { Surface air } \\
\text { temperature }\end{array}$ & $\begin{array}{c}\text { Accuracy: } \\
\pm 1 \mathrm{~K}\end{array}$ & $\begin{array}{c}\text { Range: } \\
140-280 \mathrm{~K} \\
\text { Accuracy: } \\
\pm 1 \mathrm{~K} \\
\text { Resolution: } \\
0.5 \mathrm{~K}\end{array}$ & $\begin{array}{c}\text { Range: } \\
\text { 150-300 K } \\
\text { Accuracy: } \\
5 \mathrm{~K} \\
\text { Resolution: } \\
0.1 \mathrm{~K}\end{array}$ & $\begin{array}{c}\text { Range: } \\
-124-55^{\circ} \mathrm{C}(149-328 \mathrm{~K}) \\
\text { Accuracy: } \\
\pm 0.68 \mathrm{~K} \\
\text { Resolution } \\
0.1 \mathrm{~K}\end{array}$ \\
\hline Pressure & $\begin{array}{l}\text { Inside the Lander body } \\
\text { Accuracy: } \\
<1 \mathrm{~Pa}\end{array}$ & $\begin{array}{l}\text { Range: } \\
0-5 \mathrm{hPa} \\
\text { Accuracy: } \\
\pm 10 \%\end{array}$ & $\begin{array}{c}\text { Range: } \\
\text { 4-14 hPa } \\
\text { Accuracy: } \\
\text { 3.5 Pa (root-mean-square) } \\
\text { Resolution: } \\
0.2 \mathrm{~Pa}\end{array}$ & $\begin{array}{c}\text { Range: } \\
1 \text { Pa-20 hPa } \\
\text { Accuracy: } \\
\pm 0.35 \% \text { F.S. }( \pm 7 \mathrm{~Pa}) . \\
\text { Resolution: } \\
0.076 \mathrm{~Pa}\end{array}$ \\
\hline
\end{tabular}

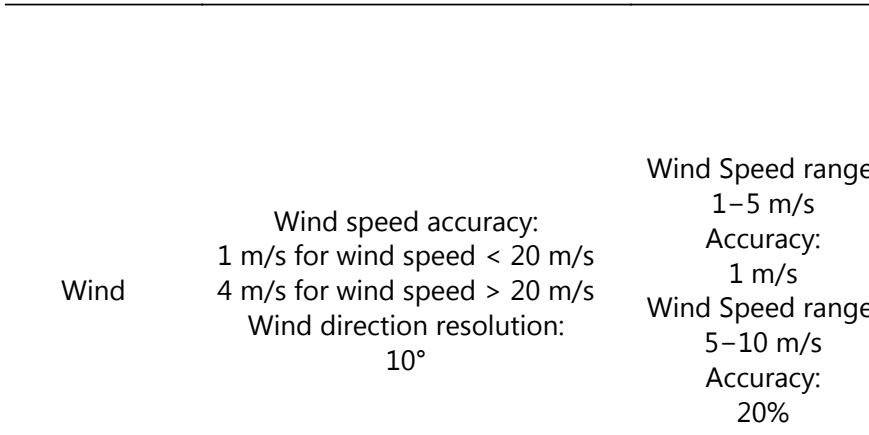

$\begin{array}{cc}\text { Wind Speed range: } & \\ 0-70 \mathrm{~m} / \mathrm{s} & \\ \text { Resolution: } & \\ 0.5 \mathrm{~m} / \mathrm{s} & \text { Wind Speed range: } \\ \text { Accuracy: } & 1-70 \mathrm{~m} / \mathrm{s} . \\ 1 \mathrm{~m} / \mathrm{s} & \text { Accuracy: } \\ \text { Horizontal wind direction } & 1.9 \mathrm{~m} / \mathrm{s} \\ \text { Wind Speed range: } & \text { Wind direction range: } \\ 0-20 \mathrm{~m} / \mathrm{s} & 0^{\circ}-360^{\circ} \\ \text { Resolution: } & \text { Wind direction accuracy: } \\ 0.5 \mathrm{~m} / \mathrm{s} & 15^{\circ} \\ \text { Accuracy: } & \end{array}$

$1 \mathrm{~m} / \mathrm{s}$
Vertical wind direction

Wind direction accuracy: $30^{\circ}$

\begin{tabular}{|c|c|c|c|c|}
\hline Sound & $\mathrm{N} / \mathrm{A}$ & Not turned on & N/A & $\begin{array}{c}\text { Sensitivity: } \\
68.14 \text { mV/Pa@250 Hz } \\
\text { Dynamic range: } \\
96.12 \mathrm{~dB} .\end{array}$ \\
\hline
\end{tabular}

\section{Acknowledgments}

This work is supported by funding from the China State Administration of Science Technology and Industry for National Defense.

\section{References}

Chamberlain, T. E., Cole, H. L., Dutton, R. G., Greene, G. C., and Tillman, J. E. (1976). Atmospheric measurements on Mars: the Viking Meteorology Experiment. Bull. Amer. Meteor. Soc., 57(9), 1094-1105. https://doi.org/10.1175/1520-0477(1976)057<1094:AMOMTV>2.0.CO;2

Delory, G. T., Luhmann, J., Friedman, L., and Betts, B. (2007). Development of the first audio microphone for use on the surface of mars. J. Acoust. Soc. Am., 121(5), 3116. https://doi.org/10.1121/1.4782072

Domínguez, M., Ricart, J., Kowalski, L., Torres, J., Navarro, S., Romeral, J., and Castañer, L. (2008). A hot film anemometer for the Martian atmosphere. Planet. Space Sci., 56(8), 1169-1179. https://doi.org/10.1016/j.pss.2008.02.013

Gómez-Elvira, J., Armiens, C., Castañer, L., Domínguez, M., Genzer, M., Gómez, F., Haberle, R., Harri, A.-M., Jiménez, V., ... Martín-Torres, J. (2012). REMS: The environmental sensor suite for the mars science laboratory rover. Space Sci. Rev., 170(1-4), 583-640. https://doi.org/10.1007/s11214-012-9921-1

Gunnlaugsson, H. P., Holstein-Rathlou, C., Merrison, J. P., Jensen, S. K., Lange, C. F., Larsen, S. E., Madsen, M. B., Nørnberg, P., Bechtold, H., ... Smith, P. (2008). Telltale wind indicator for the Mars Phoenix lander. J. Geophys. Res. Planets, 113(E3), E00A04. https://doi.org/10.1029/2007JE003008

Incropera, F. P., Dewitt, D. P., Bergman, T. L., and Lavine, A. S. (2007). Fundamentals of Heat and Mass Transfer (pp. 350). Hoboken: John Wiley \&
Sons, Inc.

InSight Mission News. (2018). NASA InSight Lander 'Hears' Martian Winds. http://mars.nasa.gov/news/8397/nasa-insight-lander-hears-martianwinds/?site=insight.

InSight Mission News. (2019). NASA's InSight 'Hears' Peculiar Sounds on Mars. http://mars.nasa.gov/news/8517/nasa-insight-lander-hears-peculiarsounds-on-mars/?site=insight.

Kasting, J. F. (1991). CO ${ }_{2}$ condensation and the climate of early Mars. Icarus, 94(1), 1-13. https://doi.org/10.1016/0019-1035(91)90137-I

Lorenz, R. D. (2004). Planetary probe entry and descent instrumentation-a review. In Proceedings of the International Workshop on Planetary Entry and Descent Trajectory Reconstruction and Science (pp. 49-56). Lisbon: European Space Agency.

Mahaffy, P. R., Webster, C. R., Atreya, S. K., Franz, H., Wong, M., Conrad, P. G., Harpold, D., Jones, J. J., Leshin, L. A., ... MSL Science Team. (2013). Abundance and isotopic composition of gases in the Martian Atmosphere from the Curiosity Rover. Science, 341(6143), 263-266. https://doi.org/10.1126/science.1237966

Mueller, D. W. Jr., and Abu-Mulaweh, H. I. (2006). Prediction of the temperature in a fin cooled by natural convection and radiation. Appl. Therm. Eng., 26(14-15), 1662-1668. https://doi.org/10.1016/j.applthermaleng.2005.11.014

Murdoch, N., Chide, B., Lasue, J., Cadu, A., Sournac, A., Bassas-Portús, M., Jacob, X., Merrison, J., Iversen, J. J., ... Mimoun, D. (2019). Laser-induced breakdown spectroscopy acoustic testing of the Mars 2020 microphone. Planet. Space Sci., 165, 260-271. https://doi.org/10.1016/j.pss.2018.09.009 Pont, G., et al. (2018). Seis on his way to Mars. 69th IAC-18, A3, 3B, 5, x44032, 1-9. Seiff, A., Tillman, J. E., Murphy, J. R., Schofield, J. T., Crisp, D, Barnes, J. R., LaBaw, 
C., Mahoney, C., Mihalov, J. D., ... Haberle, R. (1997). The atmosphere structure and meteorology instrument on the Mars Pathfinder lander. J. Geophys. Res. Planets, 102(E2), 4045-4056.

https://doi.org/10.1029/96JE03320

Sullivan, R., Greeley, R., Kraft, M., Wilson, G., Golombek, M., Herkenhoff, K., Murphy, J., and Smith, P. (2000). Results of the Imager for Mars Pathfinder windsock experiment. J. Geophys. Res. Planets, 105(E10), 24547-24562. https://doi.org/10.1029/1999JE001234

Taylor, P. A., Catling, D. C., Daly, M., Dickinson, C. S., Gunnlaugsson, H. P., Harri, A. M., and Lange, C. F. (2008). Temperature, pressure, and wind instrumentation in the Phoenix meteorological package. J. Geophys. Res.
Planets, 113(E3), E00A10. https://doi.org/10.1029/2007JE003015

Towner, M. C., Patel, M. R., Ringrose, T. J., Zarnecki, J. C., Pullan, D., Sims, M. R., Haapanala, S., Harri, A.-M., Polkko, J., ... Garry, J. R. C. (2004). The Beagle 2 environmental sensors: science goals and instrument description. Planet. Space Sci., 52(13), 1141-1156. https://doi.org/10.1016/j.pss.2004.07.015

Williams, J. P. (2001). Acoustic environment of the Martian surface. J. Geophys. Res. Planets, 106(E3), 5033-5041. https://doi.org/10.1029/1999JE001174

Zhang, J. R., and Zhao, T. Y. (1987). Handbook of Thermophysical Properties of Engineering Commonly used Materials (pp. 272) (in Chinese). Beijing: New Times Press. 